\title{
Preferential epithelial expression of type-1 cannabinoid receptor (CB1R) in the developing canine embryo
}

\author{
Andrea Pirone, Carla Lenzi, Alessandra Coli, Elisabetta Giannessi, Maria Rita Stornelli and Vincenzo Miragliotta*
}

\begin{abstract}
The use of cannabinoid receptor agonists is gaining a strong interest both in human and veterinary medicine. The potential use of cannabimimetic compounds in companion animals was reviewed in 2007 for their role in tissue inflammation and pain. A better knowledge of type-1 cannabinoid receptor (CB1R) expression on the target population may help in risk management in order to prevent unwanted side effects. We used 30-days old canine embryos to describe the distribution of CB1R by means of immunohistochemistry with a commercially available antibody. CB1R immunoreactivity was mainly epithelial and included most structures of central and peripheral nervous system, inner ear, olfactory epithelium and related structures, eye and thyroid. Further investigative research on the role of the endocannabinoid system in the developmental biology field is needed, however, we show that in the canine species we must consider pregnancy as risk condition for developmental abnormalities that may arise upon the use of CB1R receptor agonists.
\end{abstract}

Keywords: Cannabinoid receptor 1, Embryo, Dog, Immunohistochemistry

\section{Background}

Cannabinoid receptor 1 (CB1R) is a G-protein coupled receptor that mediates the effects of $\Delta$ 9-tetrahydrocannabinol $\left(\Delta^{9} \mathrm{THC}\right)$, the most potent psychotropic constituent of cannabis sativa (Xie et al. 2012; Razdan 1986). Since its discovery in 1990 (Matsuda et al. 1990), a "peripheral" receptor was also characterised [i.e., type-2 cannabinoid receptor (CB2R)] (Munro et al. 1993); CB1R and CB2R, together with a family of endogenous lipid ligands and the machinery for their biosynthesis and metabolism, are part of the endocannabinoid system (Skaper and Di Marzo 2012).

The role of CB1R and endocannabinoid signalling has been extensively studied in the adult nervous system: $\mathrm{N}$-arachidonoylethanolamide (AEA) and 2-arachidonoylglycerol (2-AG) are the principal natural CB1R agonists able to mediate a retrograde synaptic signalling (Kano et al. 2009) causing inhibition of neurotransmitter release

*Correspondence: vincenzo.miragliotta@unipi.it

Department of Veterinary Sciences, University of Pisa, Viale Delle Piagge 2, 56124 Pisa, Italy by presynaptic neurons (Elphick and Egertova 2001). Despite the ubiquitous expression of CB1R (Katona 2009), autoradiographic analysis of the brain distribution of $\left({ }^{3} \mathrm{H}\right) \mathrm{CP}-55,940$ (a potent $\Delta^{9} \mathrm{THC}$ developed by Pfizer Inc., Groton, CT USA) (Herkenham et al. 1991a, 1991b) together with immunocytochemical investigations using different antibodies showed the highest concentrations of cannabinoid binding sites in the basal ganglia and cerebellum (Egertova et al. 1998; Egertova and Elphick 2000; Tsou et al. 1998; Pettit et al. 1998).

Recent research on the role played by the endocannabinoid system in reproduction was mostly focused on gametogenesis (Grimaldi et al. 2013; El-Talatini et al. 2009) and early events leading to the establishment of pregnancy (Melford et al. 2014): it is reported that high levels of CB1R ligands impair reproductive function causing retarded embryo development, fetal loss and pregnancy failure (Paria et al. 2001; Maccarrone et al. 2002; Maccarrone 2009). Also, absence of mediators are known to adversely affect peri-implantation embryonic development as confirmed by studies in CB1R $-/-$ mice (Wang et al. 2004) sanctioning that the CB1R mediated

\section{Springer}

(C) 2015 Pirone et al. This article is distributed under the terms of the Creative Commons Attribution 4.0 International License (http://creativecommons.org/licenses/by/4.0/), which permits unrestricted use, distribution, and reproduction in any medium, provided you give appropriate credit to the original author(s) and the source, provide a link to the Creative Commons license, and indicate if changes were made. 
signalling is essential for regular embryo development with any deviation from physiological expression leading to adverse events.

Despite pregnant bitches are unlikely to be exposed to $\Delta^{9} \mathrm{THC}$, it is possible that CB1R agonists will be used in the future as therapeutic options for treatment of different disorders (Smith et al. 2010). The CB1R/CB2R receptor agonist, $\Delta 9$-tetrahydrocannabinol $(\Delta 9$-THC; dronabinol; Marinol) and its synthetic analogue, Nabilone (Cesamet), were approved over 25 years ago as medicines for suppressing nausea and vomiting produced by chemotherapy. Sativex, (GW pharmaceuticals), a drug containing both $\Delta^{9} \mathrm{THC}$ and cannabidiol was licensed in 2010 in the UK and Canada for the treatment of spasticity due to multiple sclerosis in humans and was recently approved in several other countries. Targeting the endocannabinoid system with cannabinoid receptor agonists is yet under investigation for several possible additional therapeutic targets (Pertwee 2012).

The potential use of cannabimimetic compounds in companion animals was reviewed in 2007 for their role in tissue inflammation and pain (Re et al. 2007): palmidrol [(palmitoylethanolamide (PEA)], an AEA analogue, resulted in resolution of clinical signs in cats with eosinophilic granuloma (Scarampella et al. 2001). We recently reported CB1R expression in different cell types of normal canine skin (Campora et al. 2012) and increased levels of PEA and other bioactive lipid mediators in canine atopic dermatitis thus supporting the hypothesis of a protective role of these compounds during this inflammatory process (Abramo et al. 2014).

Potential adverse events might be managed if a better understanding of CB1R anatomical pattern is known: for this reason, this study aims to describe the morphological distribution of CB1R in canine embryos by means of immunohistochemistry.

\section{Results}

Immunoreactivity against CB1R was found in most epithelial structures while the mesenchyme was always found to be devoid of staining (Fig. 1, top image). Strongly stained structures were found in the developing nervous system, sensory organs (primordia of eyes, inner ear related structures and olfactory nerves) and thyroid.

\section{Nervous system}

Numerous CB1R immunoreactive fibers were detected. Some ganglial structures showed cytoplasmic immunoreactivity. The forebrain showed a dense plexus of positive fibres which seemed to arise from the primordia of olfactory bulbs (Fig. 2a). Choroidal plexa also showed the presence of CB1R as cytoplasmic immunostaining (Fig. 2b). Strong immunoreactivity was observed throughout the hindbrain in the section including primordia of medulla oblongata and of the pons. Two sets of fibres were anatomically visible: rostro-caudal fibres

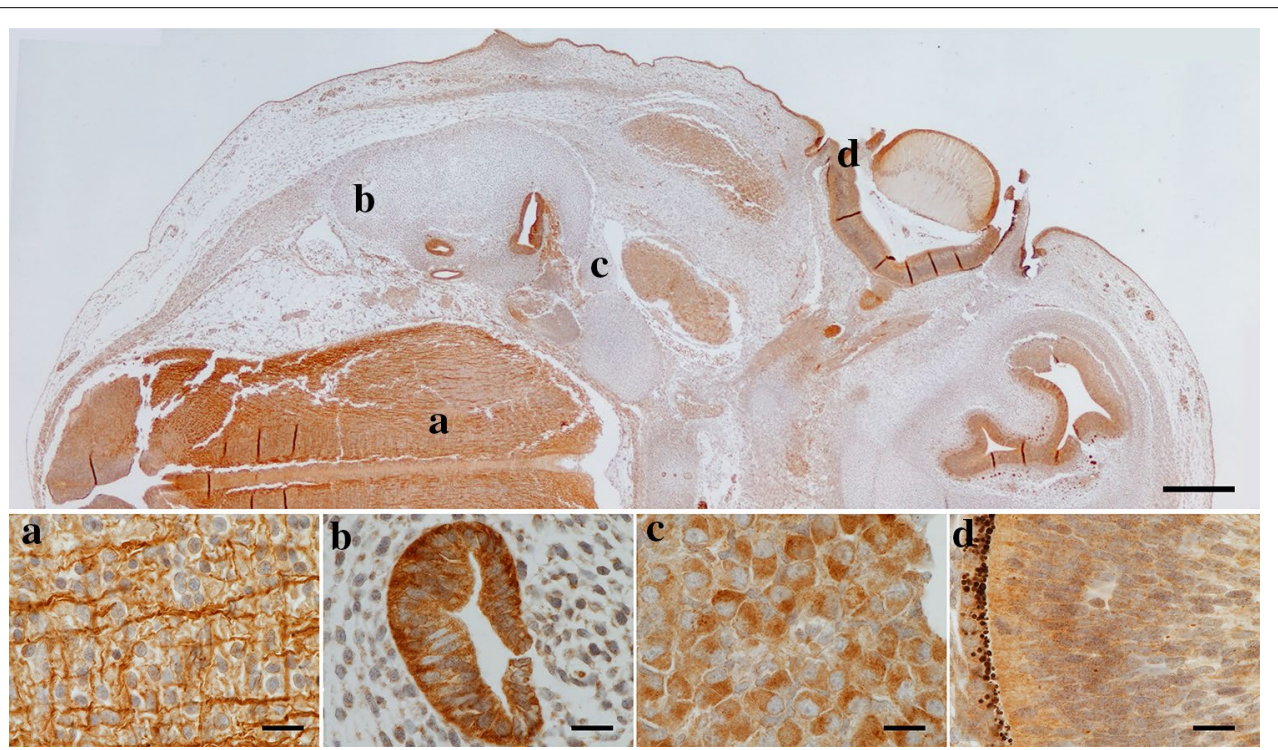

Fig. 1 Photomicrographs of the developing canine embryo. The image on top shows all the structures (low magnification) that are enlarged in $\mathbf{a}-\mathbf{d}$; $\mathbf{a}$ high magnification of the parasagittal area of the hindbrain where rostro-caudal fibres and transverse fibres are visible; $\mathbf{b}$ high magnification of the developing semi-circular canal (transverse section) where epithelial immunoreactivity is visible as cytoplasmic staining; c high magnification of the cochlear ganglion showing cytoplasmic immunostaining of cell bodies; $\mathbf{d}$ high magnification of the outer layer of the optic cup (future pigmented layer of retina) showing cytoplasmic immunoreactivity. Scale bar is $500 \mu \mathrm{m}$ in the top image and $20 \mu \mathrm{m}$ in a-d 


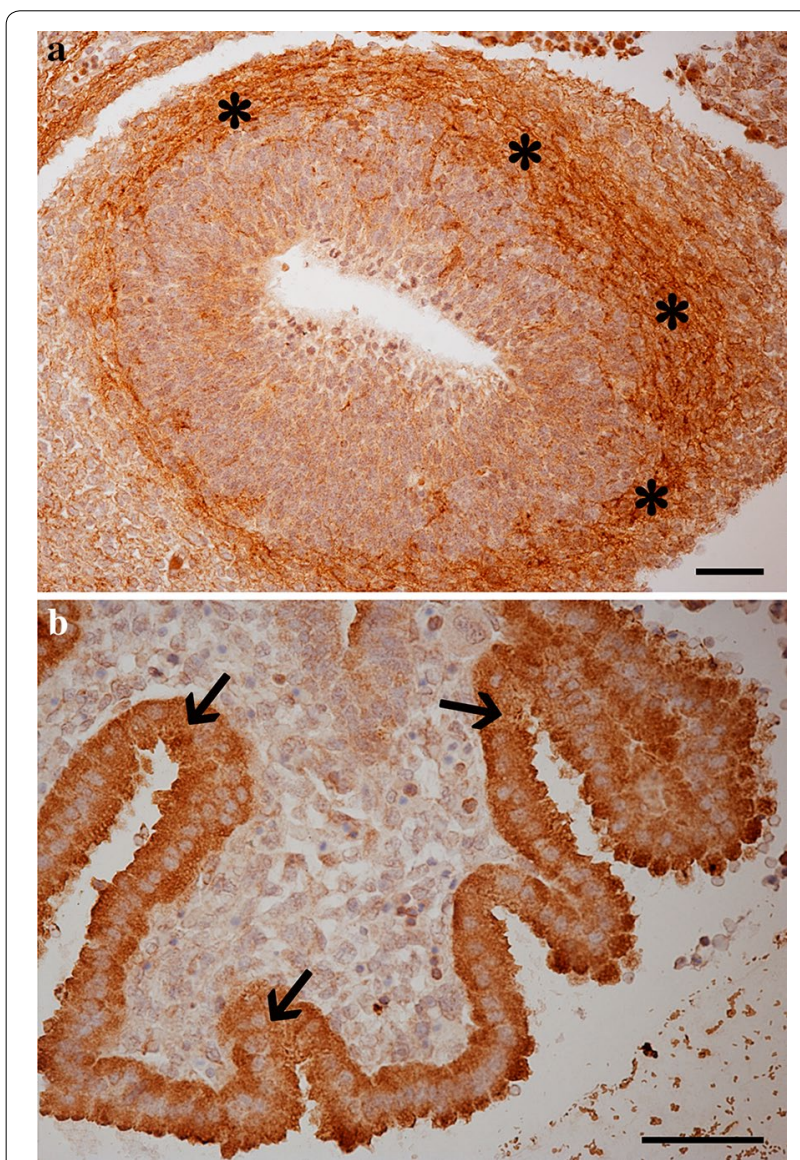

Fig. 2 Photomicrographs of the developing central nervous system focusing at the olfactory bulbs (a) and choroidal plexa (b). a asterisks indicate positive fibres in the developing olfactory cortex; $\mathbf{b}$ arrows indicate cytoplasmic immunostaining of choroidal plexa epithelial cells. Scale bars are equal to $50 \mu \mathrm{m}$

and transverse fibres. While rostro-caudal fibres were covering the entire hindbrain (excluding the medullary raphe), transverse fibres were located in the parasagittal area. Fibres crossing the medullary raphe were also visible (Figs. 1a, 3a, b). The developing spinal cord showed CB1R immunoreactivity in its white matter and most of the nerve fibres visible in the embryo body were always stained (not shown).

\section{Inner ear primordia}

Both the lateral and posterior semi-circular canals, the endo-lymphatic sac and the vestibulocochlear nerve showed intense membrane immunoreactivity (Fig. 4a, b). The vestibulocochlear ganglion showed a more intense cytoplasmic staining in its cochlear portion, while the vestibular portion was almost devoid of staining (Fig. 4b, c). The trigeminal ganglion, adjacent to the cochlear one, showed a strong cytoplasmic staining as well (Fig. 4b, d).

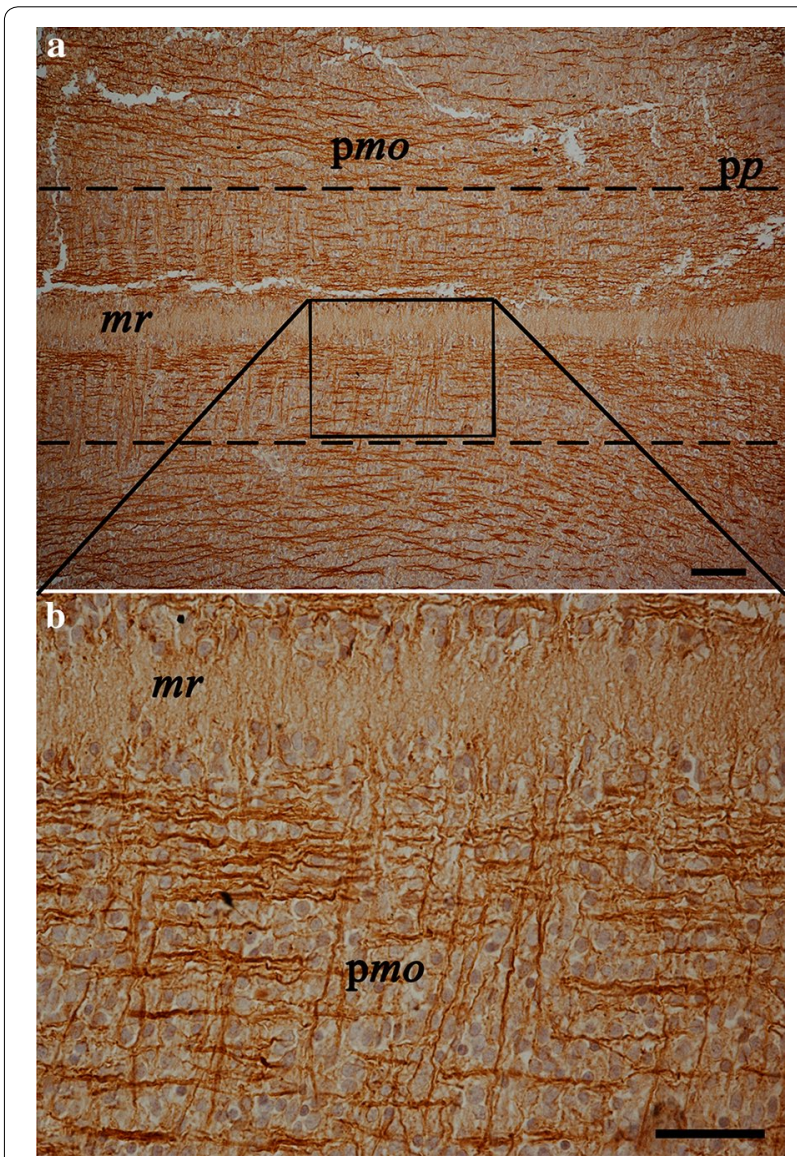

Fig. 3 Photomicrographs of the developing central nervous system focusing at the hindbrain; a low magnification of primordia of medulla oblongata ( $p m o$ ) and of the pons ( $p p)$; $m r$ indicates medullary raphe; dashed lines enclose the parasagittal area where transversal immunoreactive fibres were observed (enlarged in $\mathbf{b}$ ). b high magnification of the square represented in $\mathbf{a}$ to show both longitudinal and transversal positive fibres. Scale bars are equal to $100 \mu \mathrm{m}(\mathbf{a})$ and $50 \mu \mathrm{m}(\mathbf{b})$

\section{Primordium of the eye}

Immunoreactivity was observed as cytoplasmic labeling in both the surface epithelium and the mesothelial layer (region of future substantia propria) of cornea, and the cuboidal epithelium covering the anterior part of the lens (Fig. 5a). The inner (neural) layer of the optic cup (future nervous layer of retina) as well the outer layer (future pigment layer of retina) showed CB1R immunostaining in cell cytoplasm (Fig. 5b). The developing optic nerve was strongly marked (Fig. 5b).

\section{Primordia of the nasal cavities}

The olfactory epithelium showed cytoplasmic immunoreactivity; the underlying mesenchyme was devoid of staining but showed intense immunoreactivity of 

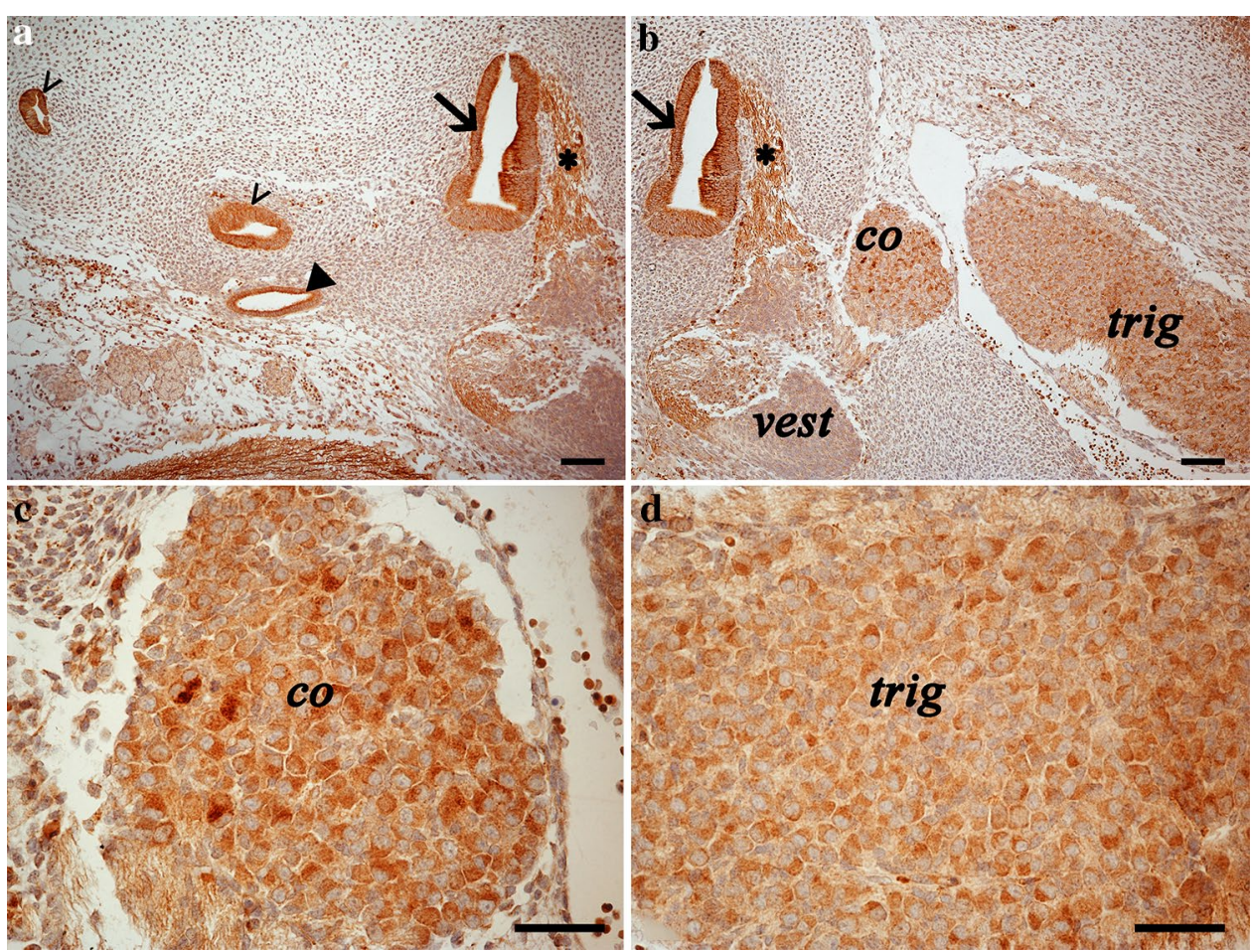

Fig. 4 Photomicrographs of the developing inner ear and associated/adjacent nervous structures. Empty arrowheads indicate semi-circular canals $(\mathbf{a}, \mathbf{b})$; Full arrowhead indicate the endo-lymphatic sac $(\mathbf{a})$; Arrow indicates the saccular area $(\mathbf{a}, \mathbf{b})$; Asterisk indicates the vestibulocochlear nerve immunostained fibres $(\mathbf{a}, \mathbf{b})$. while the trigeminal (trig) and the cochlear (co) ganglia showed cytoplasmic labelling, the vestibular ganglion (vest) was negative to CB1R presence. $\mathbf{c}$ high magnification of the cochlear (co) ganglion; $\mathbf{d}$ high magnification of the trigeminal (trig) ganglion. Scale bars are equal to $100 \mu \mathrm{m}$ in $\mathbf{a}, \mathbf{b}$ and to $50 \mu \mathrm{m}$ in $\mathbf{c}, \mathbf{d}$

the abundantly represented olfactory nerve branches (Fig. 5c).

\section{Thyroid}

Strong immunoreactivity was observed in the thyroid primordium. Immunostaining was located in cell cytoplasm and membranes (Fig. 6).

\section{Discussion}

Here we report for the first time the immunohistochemical localization of CB1R in the developing canine embryo. In developing rat embryos, CB1R messenger RNA was found in some cells of the neural tube, in several structures of the central and peripheral nervous system, in the retina as well as in two endocrine organs, the thyroid gland and the adrenal gland (Buckley et al. 1998). Our results on CB1R protein expression in canine embryos corroborate some of the above mentioned findings.

Firstly, we found several central and peripheral nervous system structures to express CB1R. Previous studies reported CB1R expression to be spatio-temporally subsequent to neuronal differentiation in the early chick embryo (Begbie et al. 2004); an analogue of $\Delta^{9} \mathrm{THC}$ was then reported to disrupt neural development in chick embryos (Psychoyos et al. 2008). Independent studies concurrently reported that CB1R is required for normal neuronal differentiation, axonal growth and pathfinding during neural development (Watson et al. 2008; Berghuis et al. 2007). A recent study identified SCG10/stathmin-2, a microtubule-binding protein, as the first $\Delta^{9} \mathrm{THC}$ sensitive molecular effector modulating directional growth of corticofugal axons in the developing cerebrum (Tortoriello et al. 2014).

Then we focused on sensory organs, such as inner ear structures, the developing eye and the olfactory epithelium. Several nervous and non-nervous structures resulted to express CB1R.

Although morphological studies on the role played by endocannabinoids in the auditory system are scarce, it is reported that CB1R mRNA is expressed in the cochlear ganglion of the chick (Stincic and Hyson 2011). This is in accordance with our immunohistochemical data that showed an analogous pattern of staining in the canine embryos.

We showed different structures in the developing eye of canine embryos expressing CB1R. In the same view, 


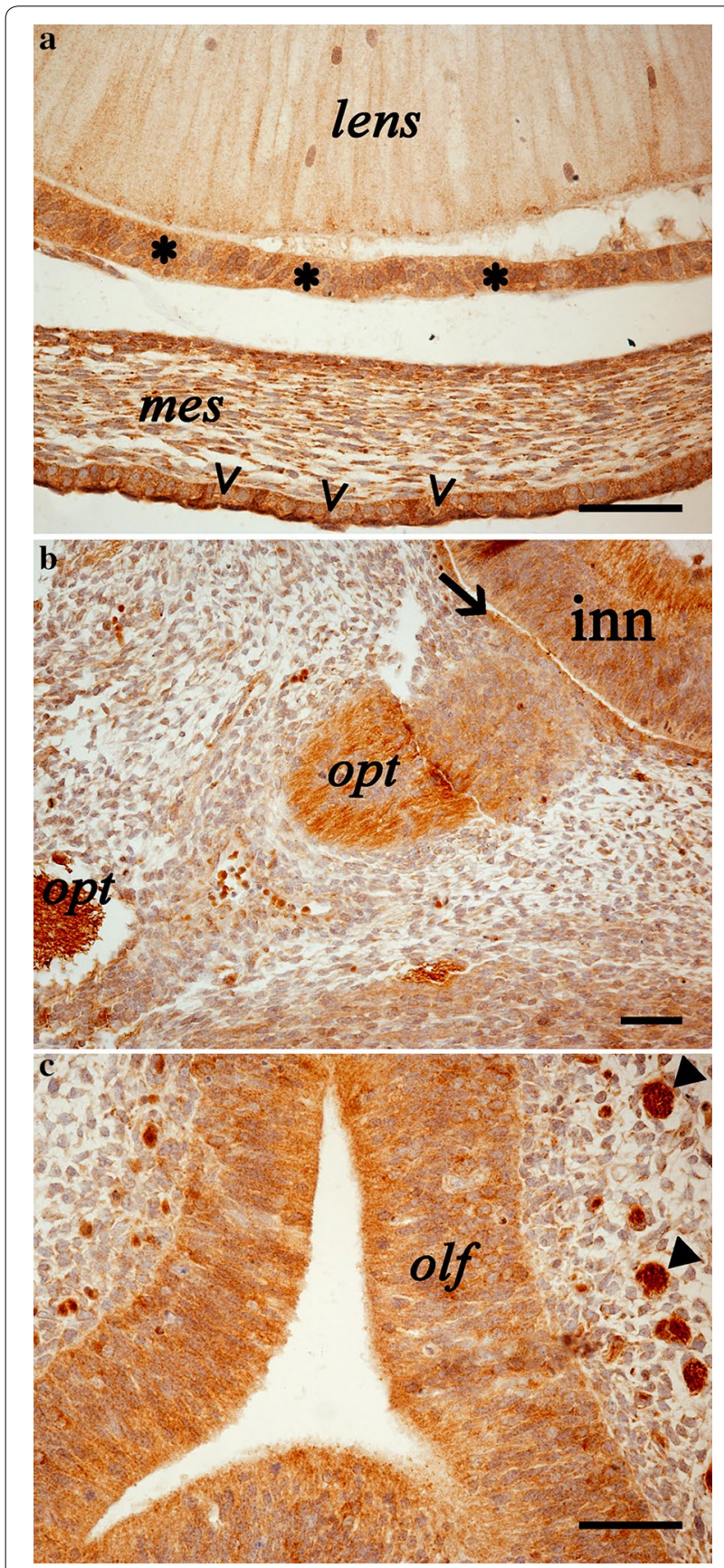

Fig. 5 Photomicrographs of the developing eye $(\mathbf{a}, \mathbf{b})$ and nasal cavities. a CB1R labelling is visible in the epithelium comprising the capsule of the lens (asterisks), in the cell cytoplasm of the mesothelial layer of the cornea (mes) and in the surface epithelium of cornea (arrowheads); b CB1R immunoreactive fibres of the optic nerve (opt), the inner (inn) and outer (arrow) layer of the optic cup (future nervous and pigmented layer of retina) are shown; c CB1R reactivity is visible in the olfactory epithelium (o/f) and in the olfactory nerve branches (full arrowheads). Scale bars are equal to $50 \mu \mathrm{m}$
Buckley and colleagues found the embryonic rat retina to express CB1R receptor mRNA (Buckley et al. 1998). Further works on the CB1R localization in the eye structures are available in adult rats and humans (Straiker et al. 1999; Yazulla et al. 1999). Taken together these data suggest that the wide distribution CB1R in both the anterior eye and the retina of dogs (present study) and humans (Straiker et al. 1999) may account for an influence of the endocannabinoid system in several different physiological functions of the vision.

With regard to the olfactory epithelium, some data are available in Xenopus laevis tadpoles (Czesnik et al. 2007). The mentioned paper shows localization of CB1R-like immunoreactivity on dendrites of olfactory receptor neurons: our data show analogous findings since both the canine embryo olfactory epithelium and the underlying olfactory nerve branches resulted to express the protein.

As stated above, the same work of Buckley et al. showed the thyroid gland and the adrenal gland to express CB1R mRNA in the rat embryo (Buckley et al. 1998). Although we did not find CB1R expression in the developing adrenal glands of canine embryos, thyroid was amongst the major immunostained organs.

Depending on the examined structure, different cellular localization of CB1 were recorded: in particular, while the cytoplasmic compartment was always immunoreactive, we found membrane distribution in the developing thyroid gland. To this regard our study does not allow for mechanistic hypotheses and, although CB1 spatial segregation is likely to affect receptor activity, it is reported that also intracellular CB1 receptors are functional (Rozenfeld and Devi 2008).

\section{Conclusions}

Our work may serve as a basis for further investigative research on the role of the endocannabinoid system in the developmental biology field; also, we show that in the canine specie several developing structures express CB1R. This latter finding should be considered in the use of already available cannabinomimetic compounds. Further investigations are needed to clarify the physiological role of CB1R during canine embryo development.

\section{Methods}

\section{Animals}

Six canine embryos obtained from two different mothers subjected to hysterectomy were used in the present study. Embryos were graded as 30-days-old based on their morphology according to Miller's Anatomy of the Dog (Evans 


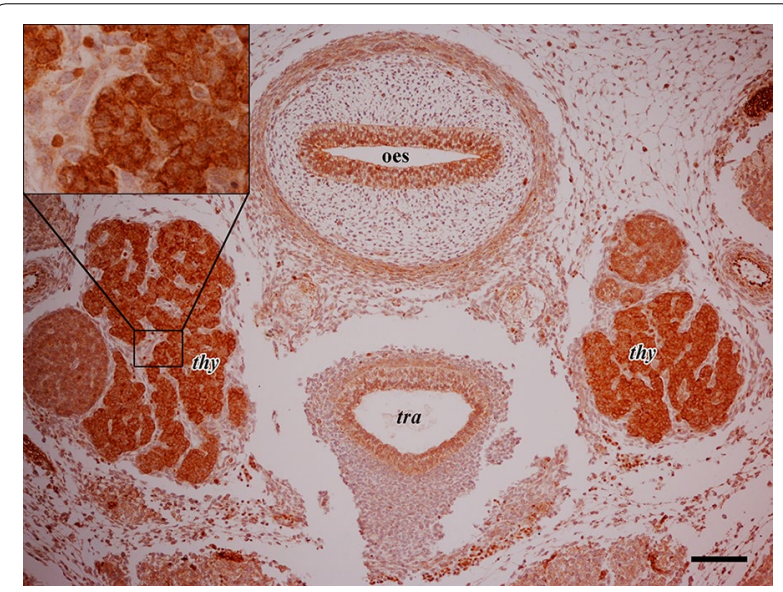

Fig. 6 Photomicrographs of the developing thyroid (thy). Oesophagus (oes), trachea (tra) show epithelial staining. Left and right lobes of thyroid (thy) show intense cytoplasm/membrane staining of epithelial cells. Inset is an high magnification to better demonstrate subcellular localization of CB1R immunoreactivity. Scale bar is equal to $100 \mu \mathrm{m}$
1993). Briefly, the entire pregnant uterus was removed during surgery and promptly immersed in $10 \%$ buffered formalin solution. Embryos were dissected after $24 \mathrm{~h}$ and kept in fresh $10 \%$ buffered formalin solution for $48 \mathrm{~h}$. Embryos were thus processed for routine paraffin embedding. Serial $5 \mu \mathrm{m}$ transverse sections were obtained and stained for either morphological (routine Haematoxylin and Eosin staining) or immunohistochemical evaluation of CB1R distribution. Sections were selected in order to include primordia of all the organs present at this embryonic stage.

This research was carried out according to the international regulation on the use of animals for scientific purposes (Directive 2010/63/EU) and all experimental procedures were approved by the local ethical committee.

\section{Immunohistochemical procedure}

Immunohistochemistry was performed on serial sections using a rabbit polyclonal anti-Cannabinoid Receptor I antibody (1:50, abcam, ab23703); a synthetic peptide corresponding to $\mathrm{C}$ terminal amino acids 461-472 of Human Cannabinoid Receptor was used to raise the antibody Epitope retrieval was carried out at $120{ }^{\circ} \mathrm{C}$ in a pressure cooker for 5 min with a Tris/EDTA buffer pH 9.0. Sections were pretreated in $1 \% \mathrm{H}_{2} \mathrm{O}_{2}$ (in $0.1 \mathrm{M} \mathrm{PBS}, \mathrm{pH} 7.4$, $10 \mathrm{~min}$ ) to quench endogenous peroxidase activity, then rinsed with $0.05 \%$ tween-20 detergent (in 0.1 M PBS, $3 \times 10 \mathrm{~min}$.), and blocked with $5 \%$ goat normal serum (s-1000, Vector) (in $0.1 \mathrm{M} \mathrm{PBS,} 1 \mathrm{~h}$ ). Sections were incubated overnight at $4{ }^{\circ} \mathrm{C}$ in a solution containing the rabbit anti-CB1R, $2 \%$ goat normal serum, $0.05 \%$ triton X-100 (in $0.1 \mathrm{M}$ PBS). Subsequently they were rinsed in $0.1 \mathrm{M}$ PBS, $(3 \times 10 \mathrm{~min})$, followed by $1 \mathrm{~h}$ incubation with a biotinylated goat anti-rabbit immunoglobulin (BA-1000, Vector Labs, Burlingame, CA), diluted 1:300 in PBS. Sections were again rinsed in $0.1 \mathrm{M} \mathrm{PBS}, 3 \times 10 \mathrm{~min}$. After $1 \mathrm{~h}$ incubation with the ABC complex (pk-7200, Vector, Burlingame, CA) followed by further washes in $0.1 \mathrm{M}$ PBS, (3 x $10 \mathrm{~min}$ ) staining was visualized by incubating the sections in diaminobenzidine (DAB) (sk-4105, Vector, Burlingame, CA) solution.

Although we had already tested the primary antibody specificity in the canine specie by incubation with the corresponding peptide (Campora et al. 2012), substitution of either the primary antibody, or anti-rabbit IgG, or the ABC complex by PBS or non-immune serum was performed. Under these conditions the immunostaining was abolished.

The microphotographs were taken with a light microscope (Leitz Diaplan, Wetzlar, Germany) connected to a PC via a Nikon digital system (Digital Sight DS-U1, NISElements BR-4.13.00 software).

\section{Abbreviations}

2-AG: 2-arachidonoylglycerol; AEA: N-arachidonoylethanolamide; CB1R: type-1 cannabinoid receptor; CB2R: type-2 cannabinoid receptor; co: cochlear; $\triangle 9$-THC: $\triangle 9$-tetrahydrocannabinol; mes: mesothelial layer of the cornea; $\mathrm{mr}$ : medullary raphe; oes: oesophagus; opt: optic nerve; PEA: palmitoylethanolamide; pmo: primordia of medulla oblongata; pp: pons; thy: developing thyroid; tra: trachea; trig: trigeminal; vest: vestibular.

\section{Authors' contributions}

$A P$ and $C L$ carried out immunohistochemical staining and drafted the manuscript; AC, EG and MRS collected results and participated in drafting the manuscript; VM conceived the study, critically revised and finalised the manuscript. All authors read and approved the final manuscript.

\section{Acknowledgements}

The authors would like to thank Marco Salvadori, Alessandro Baglini and Stefania Mazzanti of the Department of Veterinary Sciences of the University of Pisa for facilitating the conduction of this study. A special thanks goes to Cono Miragliotta for his invaluable support and encouragement.

\section{Competing interests}

The authors declare that they have no competing interests.

Received: 12 May 2015 Accepted: 13 December 2015

Published online: 22 December 2015

\section{References}

Abramo F, Campora L, Albanese F, della Valle MF, Cristino L, Petrosino S, Di Marzo V, Miragliotta V (2014) Increased levels of palmitoylethanolamide and other bioactive lipid mediators and enhanced local mast cell proliferation in canine atopic dermatitis. BMC Vet Res 10:21. doi:10.1186/1746-6148-10-21

Begbie J, Doherty P, Graham A (2004) Cannabinoid receptor, CB1, expression follows neuronal differentiation in the early chick embryo. J Anat 205(3):213-218. doi:10.1111/j.0021-8782.2004.00325.x

Berghuis P, Rajnicek AM, Morozov YM, Ross RA, Mulder J, Urban GM, Monory K, Marsicano G, Matteoli M, Canty A, Irving AJ, Katona I, Yanagawa Y, Rakic 
P, Lutz B, Mackie K, Harkany T (2007) Hardwiring the brain: endocannabinoids shape neuronal connectivity. Science 316(5828):1212-1216. doi:10.1126/science.1137406

Buckley NE, Hansson S, Harta G, Mezey E (1998) Expression of the CB1 and CB2 receptor messenger RNAs during embryonic development in the rat. Neuroscience 82(4):1131-1149

Campora L, Miragliotta V, Ricci E, Cristino L, Di Marzo V, Albanese F, Federica Della Valle M, Abramo F (2012) Cannabinoid receptor type 1 and 2 expression in the skin of healthy dogs and dogs with atopic dermatitis. Am J Vet Res 73(7):988-995. doi:10.2460/ajvr.73.7.988

Czesnik D, Schild D, Kuduz J, Manzini I (2007) Cannabinoid action in the olfactory epithelium. Proc Natl Acad Sci USA 104(8):2967-2972. doi:10.1073/ pnas.0609067104

Egertova M, Elphick MR (2000) Localisation of cannabinoid receptors in the rat brain using antibodies to the intracellular C-terminal tail of CB. J Comp Neurol 422(2):159-171

Egertova M, Giang DK, Cravatt BF, Elphick MR (1998) A new perspective on cannabinoid signalling: complementary localization of fatty acid amide hydrolase and the CB1 receptor in rat brain. Proc Biol Sci 265(1410):20812085. doi:10.1098/rspb.1998.0543

Elphick MR, Egertova M (2001) The neurobiology and evolution of cannabinoid signalling. Philos Trans R Soc Lond B Biol Sci 356(1407):381-408

El-Talatini MR, Taylor AH, Elson JC, Brown L, Davidson AC, Konje JC (2009) Localisation and function of the endocannabinoid system in the human ovary. PLoS One 4(2):e4579. doi:10.1371/journal.pone.0004579

Evans HE (1993) Miller's anatomy of the dog. Saunders, WB

Grimaldi P, Di Giacomo D, Geremia R (2013) The Endocannabinoid System and Spermatogenesis. Front Endocrinol 4:192. doi:10.3389/fendo.2013.00192

Herkenham M, Groen BGS, Lynn AB, Decosta BR, Richfield EK (1991a) Neuronal Localization of Cannabinoid Receptors and 2nd Messengers in Mutant Mouse Cerebellum. Brain Res 552(2):301-310

Herkenham M, Lynn AB, Decosta BR, Richfield EK (1991b) Neuronal Localization of Cannabinoid Receptors in the Basal Ganglia of the Rat. Brain Res 547(2):267-274

Kano M, Ohno-Shosaku T, Hashimotodani Y, Uchigashima M, Watanabe M (2009) Endocannabinoid-mediated control of synaptic transmission. Physiol Rev 89(1):309-380. doi:10.1152/physrev.00019.2008

Katona I (2009) Endocannabinoid receptors: CNS localization of the CB (1) cannabinoid receptor. Curr Top Behav Neurosci 1:65-86. doi:10.1007/978-3-540-88955-7_3

Maccarrone M (2009) Endocannabinoids: friends and foes of reproduction. Prog Lipid Res 48(6):344-354. doi:10.1016/j.plipres.2009.07.001

Maccarrone M, Bisogno T, Valensise H, Lazzarin N, Fezza F, Manna C, Di Marzo V, Finazzi-Agro A (2002) Low fatty acid amide hydrolase and high anandamide levels are associated with failure to achieve an ongoing pregnancy after IVF and embryo transfer. Mol Hum Reprod 8(2):188-195

Matsuda LA, Lolait SJ, Brownstein MJ, Young AC, Bonner TI (1990) Structure of a cannabinoid receptor and functional expression of the cloned cDNA. Nature 346(6284):561-564. doi:10.1038/346561a0

Melford SE, Taylor AH, Konje JC (2014) Of mice and (wo)men: factors influencing successful implantation including endocannabinoids. Hum Reprod Update 20(3):415-428. doi:10.1093/humupd/dmt060

Munro S, Thomas KL, Abu-Shaar M (1993) Molecular characterization of a peripheral receptor for cannabinoids. Nature 365(6441):61-65. doi:10.1038/365061a0

Paria BC, Song H, Wang X, Schmid PC, Krebsbach RJ, Schmid HH, Bonner TI, Zimmer A, Dey SK (2001) Dysregulated cannabinoid signaling disrupts uterine receptivity for embryo implantation. J Biol Chem 276(23):2052320528. doi:10.1074/jbc.M100679200

Pertwee RG (2012) Targeting the endocannabinoid system with cannabinoid receptor agonists: pharmacological strategies and therapeutic possibilities. Philos Trans R Soc Lond B Biol Sci 367(1607):3353-3363. doi:10.1098/ rstb.2011.0381

Pettit DA, Harrison MP, Olson JM, Spencer RF, Cabral GA (1998) Immunohistochemical localization of the neural cannabinoid receptor in rat brain. J Neurosci Res 51(3):391-402

Psychoyos D, Hungund B, Cooper T, Finnell RH (2008) A cannabinoid analogue of Delta9-tetrahydrocannabinol disrupts neural development in chick. Birth Defects Res B Dev Reprod Toxicol 83(5):477-488. doi:10.1002/ bdrb.20166
Razdan RK (1986) Structure-activity relationships in cannabinoids. Pharmaco Rev 38(2):75-149

Re G, Barbero R, Miolo A, Di Marzo V (2007) Palmitoylethanolamide, endocannabinoids and related cannabimimetic compounds in protection against tissue inflammation and pain: potential use in companion animals. Vet J 173(1):21-30. doi:10.1016/j.tvjl.2005.10.003

Rozenfeld R, Devi LA (2008) Regulation of CB1 cannabinoid receptor trafficking by the adaptor protein AP-3. FASEB J 22(7):2311-2322. doi:10.1096/ fi.07-102731

Scarampella F, Abramo F, Noli C (2001) Clinical and histological evaluation of an analogue of palmitoylethanolamide, PLR 120 (comicronized Palmidrol INN) in cats with eosinophilic granuloma and eosinophilic plaque: a pilot study. Vet Dermatol 12(1):29-39

Skaper SD, Di Marzo V (2012) Endocannabinoids in nervous system health and disease: the big picture in a nutshell. Philos Trans R Soc Lond B Biol Sci 367(1607):3193-3200. doi:10.1098/rstb.2012.0313

Smith TH, Sim-Selley LJ, Selley DE (2010) Cannabinoid CB1 receptor-interacting proteins: novel targets for central nervous system drug discovery? $\mathrm{Br} J$ Pharmacol 160(3):454-466. doi:10.1111/j.1476-5381.2010.00777.x

Stincic TL, Hyson RL (2011) The localization and physiological effects of cannabinoid receptor 1 in the brain stem auditory system of the chick. Neuroscience 194:150-159. doi:10.1016/j.neuroscience.2011.05.061

Straiker AJ, Maguire G, Mackie K, Lindsey J (1999) Localization of cannabinoid CB1 receptors in the human anterior eye and retina. Invest Ophthalmol Vis Sci 40(10):2442-2448

Tortoriello G, Morris CV, Alpar A, Fuzik J, Shirran SL, Calvigioni D, Keimpema E, Botting CH, Reinecke K, Herdegen T, Courtney M, Hurd YL, Harkany T (2014) Miswiring the brain: delta9-tetrahydrocannabinol disrupts cortical development by inducing an SCG10/stathmin-2 degradation pathway. EMBO J 33(7):668-685. doi:10.1002/embj.201386035

Tsou K, Brown S, Sanudo-Pena MC, Mackie K, Walker JM (1998) Immunohistochemical distribution of cannabinoid CB1 receptors in the rat central nervous system. Neuroscience 83(2):393-411

Wang H, Guo Y, Wang D, Kingsley PJ, Marnett LJ, Das SK, DuBois RN, Dey SK (2004) Aberrant cannabinoid signaling impairs oviductal transport of embryos. Nat Med 10(10):1074-1080. doi:10.1038/nm1104

Watson S, Chambers D, Hobbs C, Doherty P, Graham A (2008) The endocannabinoid receptor, CB1, is required for normal axonal growth and fasciculation. Mol Cel Neurosci 38(1):89-97. doi:10.1016/j.mcn.2008.02.001

Xie H, Sun X, Piao Y, Jegga AG, Handwerger S, Ko MS, Dey SK (2012) Silencing or amplification of endocannabinoid signaling in blastocysts via CB1 compromises trophoblast cell migration. J Biol Chem 287(38):3228832297. doi:10.1074/jbc.M112.381145

Yazulla S, Studholme KM, McIntosh HH, Deutsch DG (1999) Immunocytochemical localization of cannabinoid CB1 receptor and fatty acid amide hydrolase in rat retina. J Comp Neurol 415(1):80-90

\section{Submit your manuscript to a SpringerOpen ${ }^{\circ}$ journal and benefit from:}

- Convenient online submission

- Rigorous peer review

- Immediate publication on acceptance

- Open access: articles freely available online

- High visibility within the field

- Retaining the copyright to your article

Submit your next manuscript at $>$ springeropen.com 